\title{
Plasma-Derived Extracellular Vesicles as Potential Biomarkers in Heart Transplant Patient with Chronic Chagas Disease
}

\author{
Nuria Cortes-Serra, Maria Tays Mendes, Clara Mazagatos, ${ }^{1}$ Joan Segui-Barber, \\ Cameron C. Ellis, Cristina Ballart, Ana Garcia-Alvarez, Montserrat Gállego, \\ Joaquim Gascon, Igor C. Almeida, María Jesús Pinazo, Carmen Fernandez-Becerra
}

Chagas disease is emerging in countries to which it is not endemic. Biomarkers for earlier therapeutic response assessment in patients with chronic Chagas disease are needed. We profiled plasma-derived extracellular vesicles from a heart transplant patient with chronic Chagas disease and showed the potential of this approach for discovering such biomarkers.

Chagas disease, caused by Trypanosoma cruzi parasite, is one of the most prevalent parasitic infections in Latin America and is responsible for millions of clinical cases. However, mainly because of migratory movements, the epidemiology of Chagas disease has changed in recent decades; cases have increased substantially in North America, Europe, and Asia, where it is not endemic (1). Thus, raising awareness of this debilitating or deadly neglected tropical disease and promoting the creation of global strategies for its accurate diagnosis, treatment, and control are of paramount importance.

Detection of T. cruzi-specific antibodies in serologic assays is the current standard technique

Author affiliations: Barcelona Institute for Global Health (ISGlobal), Universitat de Barcelona, Barcelona, Spain (N. Cortes-Serra,

C. Mazagatos, J. Segui-Barber, C. Ballart, M. Gállego, J. Gascon, M.J. Pinazo, C. Fernandez-Becerra); Border Biomedical Research Center, The University of Texas at EI Paso, EI Paso, Texas USA (M.T. Mendes, C.C. Ellis, I.C. Almeida); Secció de Parasitologia, Departament de Biologia, Sanitat i Medi Ambient, Facultat de Farmàcia i Ciències de l'Alimentació, Universitat de Barcelona, Barcelona, Spain (C. Ballart, M. Gállego); Arrhythmias Unit, Hospital Clinic, University of Barcelona, Barcelona, Spain (A. Garcia-Alvarez); Institut d'Investigació en Ciències de la Salut Germans Trias i Pujol, Badalona, Spain (C. Fernandez-Becerra)

DOI: https://doi.org/10.3201/eid2608.191042 for diagnosing chronic Chagas disease. However, this so-called conventional serology is not a valid indicator of chemotherapeutic outcomes because most patients remain seropositive for 10-20 years after treatment (2). Therefore, validated biomarkers are lacking for early assessment of therapeutic responses for testing current and new drugs or treatment regimens.

Extracellular vesicles (EVs) are cell-derived membranous nanoparticles present in most biologic fluids. Biofluid-derived EVs are minimally invasive molecular tools for diagnosing and screening diseases (3). They can be released by various mammalian cells and pathogens, and their use as predictive biomarkers for disease progression and treatment outcomes has been reported for different pathologic conditions, including parasitic diseases $(3,4)$.

\section{The Study}

The Ethical Committee of Clinical Research of Hospital Clinic (Barcelona, Spain; reference no. Reg. HCB/2015/0616) approved this project. The patient provided written informed consent before sample collection.

In 2009, a 51-year-old patient from Bolivia with a history of chronic Chagas disease, exhibiting severe organ involvement (chronic cardiomyopathy Kuschnir III and megacolon and megaesophagus degree IV) (5), was admitted to the International Health Department (Hospital Clinic, Barcelona). Serologic diagnosis for chronic Chagas disease was performed using 2 ELISA kits (Ortho-Clinical Diagnostics, https://www. orthoclinicaldiagnostics.com) and BioELISA Chagas

\footnotetext{
${ }^{1}$ Current affiliation: CIBER Epidemiología y Salud Pública (CIBERESP); Centro Nacional de Epidemiología, Instituto de Salud Carlos III, Madrid, Spain.
} 
Table 1. Timeline of heart transplant patient with chronic Chagas disease from initial diagnosis to last follow-up and death*

\begin{tabular}{|c|c|c|}
\hline Date & Infection & Observation, treatment, outcome \\
\hline 2015 Aug & Cytomegalovirus, detected by serology & $\begin{array}{l}\text { Diagnosed only by positive IgG serology, no active infection (no positive } \\
\text { IgM serology). No treatment. }\end{array}$ \\
\hline 2015 Aug & Toxoplasmosis, detected by serology & $\begin{array}{l}\text { Diagnosed only by positive IgG serology, no active infection (no positive } \\
\text { IgM serology). No treatment. }\end{array}$ \\
\hline 2015 Nov & & $\begin{array}{l}\text { Heart transplantation on Nov. 28. Patient started with immunosuppressive } \\
\text { therapy (tacrolimus, azathioprine, prednisone) until the end of follow-up. }\end{array}$ \\
\hline 2016 Jan & $\begin{array}{l}\text { Chagas disease reactivation, detection } \\
\text { by qPCR }\end{array}$ & $\begin{array}{l}\text { Pretreatment sample collected on Jan } 28 \text {. Patient started BZN treatment } \\
(2.5 \mathrm{mg} / \mathrm{kg} \text {, twice a day, } 60 \mathrm{~d}) \text { on Feb } 3 .\end{array}$ \\
\hline 2016 Mar & $\begin{array}{l}\text { Bronchopulmonary aspergillosis, } \\
\text { detected by serology and CT }\end{array}$ & $\begin{array}{l}\text { BZN course interrupted on Mar } 21 \text {. Completed } 80 \% \text { of the prescribed } \\
\text { treatment. }\end{array}$ \\
\hline 2016 Mar & Bronchopulmonary aspergillosis & $\begin{array}{l}\text { Aspergillosis treatment started on Mar } 22 \text {. Initially with voriconazole and } \\
\text { amphotericin B liposomal. Treatment was changed to posaconazole until } \\
\text { the end of the follow-up. } \dagger\end{array}$ \\
\hline 2016 Apr & $\begin{array}{l}\text { Chagas disease reactivation, detected } \\
\text { by qPCR }\end{array}$ & $\begin{array}{l}\text { On Apr 14, patient started second round of BZN treatment until May } 5 \text {, } \\
\text { completing } 100 \% \text { of the prescribed treatment. }\end{array}$ \\
\hline 2016 May & & Posttreatment sample collected on May 11. \\
\hline 2016 Aug & & Late organ rejection. Patient died. \\
\hline
\end{tabular}

(Biokit, https://www.biokit.com). Together with clinical management of dysphagia and constipation, a pacemaker in the context of third-degree atrioventricular block was implanted. In July 2015, an echocardiogram revealed iterative cardiac failure and severe ventricular dysfunction (ejection fraction 15\%-20\%). On November 28, 2015, the patient underwent heart transplantation without incident, and results of followup endomyocardial biopsies showed no early signs of transplant rejection.

After transplantation and in the context of immunosuppression therapy (Table 1), quantitative PCR (qPCR) was performed weekly to detect T. cruzi in the blood (Tc-qPCR) (7). First benznidazole treatment was started when several consecutive and positive TcqPCRs confirmed Chagas disease reactivation. Three weeks after benznidazole treatment, the Tc-qPCR became negative. After completion of $80 \%$ of the treatment, bronchopulmonary aspergillosis developed, and the benznidazole course was interrupted. The Tc-qPCR became positive and a second benznidazole course was initiated; this time the patient completed the initial prescribed dose without evidence of therapeutic failure based on Tc-qPCR results. Plasma samples for purification and characterization of EVs were collected before the first benznidazole treatment and just after the second course (Table 1). Unexpectedly, the patient died in August 2016 because of a late organ rejection. Therefore, samples at 6 and 12 months posttreatment, already included in the approved protocol, were not collected.

To determine whether circulating EVs from this patient could have been used as predictive biomarkers to evaluate therapeutic response and disease outcome in the Chagas disease context, we collected pretreatment and posttreatment plasma samples, and EVs were enriched by size-exclusion chromatography (SEC) and characterized as described (8) (Figure 1 , panel A). As negative controls, plasma samples from 2 healthy donors were also subjected to SEC. We characterized eluting EVs by bead-based assay and Nanoparticle Tracking Analysis (Figure 1, panels B, C). We pooled aliquots $(100 \mu \mathrm{L})$ from SEC fractions 7-10 and determined protein composition using 2Dliquid chromatography-tandem mass spectrometry (2D-LC-MS/MS). In brief, samples were digested with trypsin and resulting peptides were resolved by high-pH reversed-phase peptide fractionation (9), followed by C18 reversed-phase nanoflow ultrahighperformance liquid chromatography coupled to a Q Exactive Plus Hybrid Quadrupole-Orbitrap Mass Spectrometer (QE Plus MS; Thermo Fisher Scientific, https://www.thermofisher.com), as described (10). Raw 2D-LC-MS/MS data were analyzed using Proteome Discoverer version 2.1.1.21 software (Thermo Fisher Scientific), followed by Scaffold perSPECtives version 4.8.7 (Proteome Software; http:/ / www.proteomesoftware.com). A protein database with combined human, T. cruzi, and potential contaminants was generated from UniProt (https://www.uniprot. org). Using a false-discovery rate $<1 \%$ and 1 unique peptide per protein, we identified 12 T. cruzi proteins and 338 human proteins (Appendix, https:/ / wwwnc.cdc.gov/EID/article/26/8/19-1042-App1. xlsx). However, when we applied the more stringent criterion of $\geq 2$ unique peptides per protein, we detected only $1 T$. cruzi protein (i.e., pyruvate phosphate dikinase [PPDK]), and 288 human proteins, of which we identified 19 only in pretreatment samples (Table 2). PPDK has been identified by proteomic 

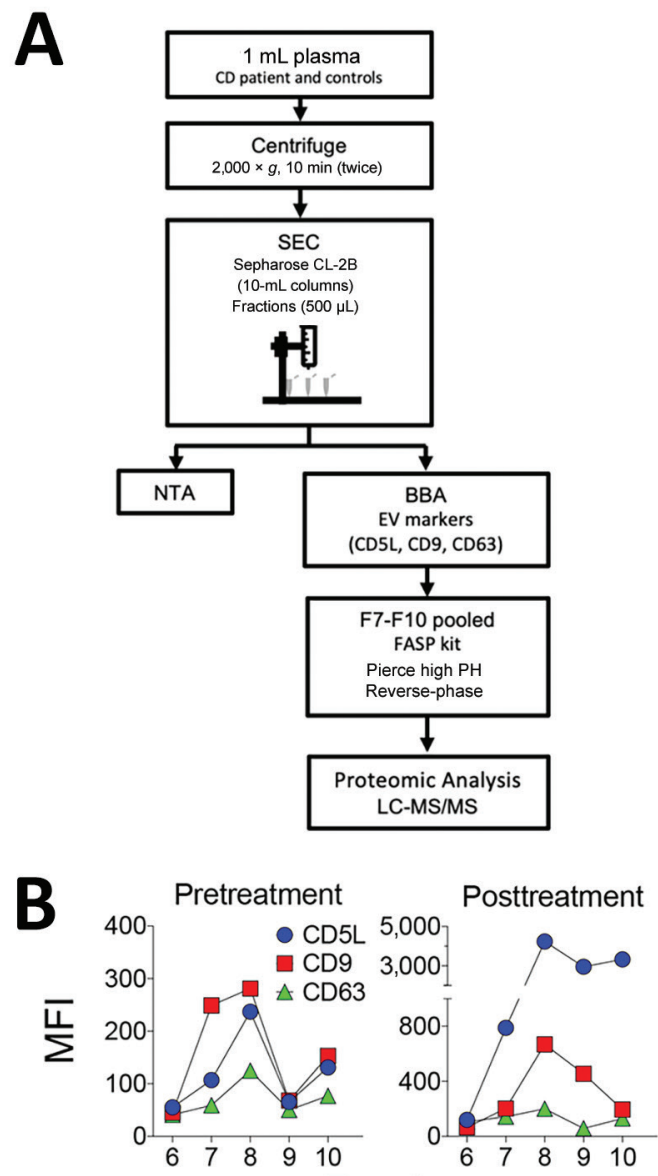

Fraction
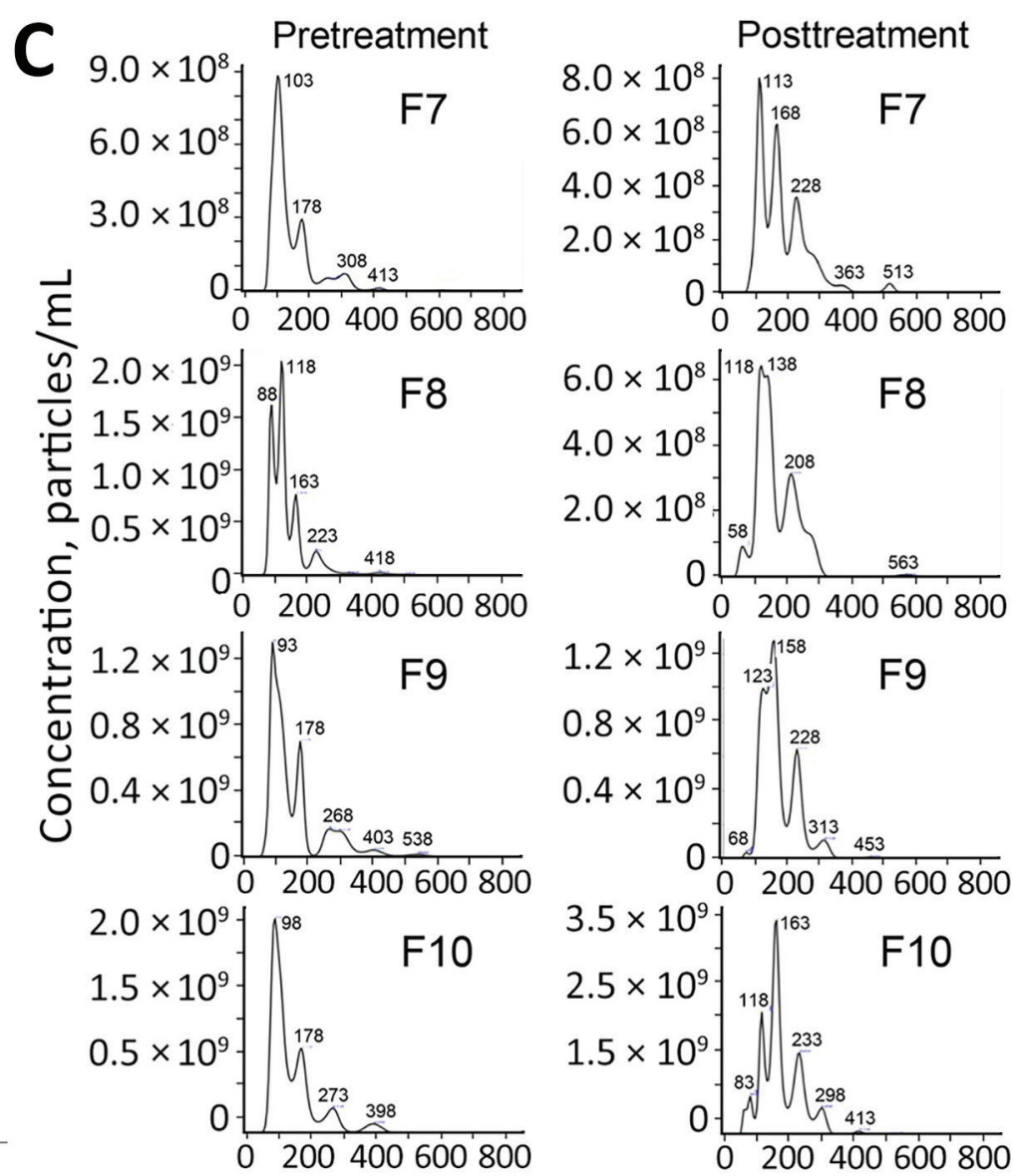

Size, $\mathrm{nm}$

Figure 1. Isolation and characterization of plasma-derived EVs. A) Schematic diagram of the isolation and characterization of EVs derived from plasma samples. The details of each step are explained in The Study section. B) EVs were characterized by BBA using the classical EV markers CD5L, CD9, and CD63. C) NTA of SEC fractions F7-10. BBA, bead-based assay; EV, extracellular vesicle; LC$\mathrm{MS} / \mathrm{MS}$, liquid chromatography-tandem mass spectrometry; MFI, median fluorescence intensity; NTA, nanoparticle tracking analysis; SEC, size-exclusion chromatography.

analysis of T. cruzi total secretome and EVs (10-12). This protein plays a central role in the metabolism of T. cruzi glycosomes and has been shown to be upregulated when trypomastigote forms are incubated with the extracellular matrix, an obligatory step before host-cell invasion and differentiation of trypomastigote into amastigote forms (13). The specific role of PPDK in EVs secreted by this patient remains to be determined.

Among the 19 human proteins uniquely identified in EVs from the patient with chronic Chagas disease before treatment, the mannan binding lectin serine protease 2 (MASP2) is worth highlighting. A recent study with human samples showed that MASP2 gene polymorphisms and MASP2 levels are associated with high risk for chronic Chagas disease cardiomyopathy (14). Furthermore, mannose-binding lectin, which activates complement on $T$. cruzi through
MASP2, has been related to a decrease in blood and tissue parasite load and in myocarditis and cardiac fibrosis in experimental T. cruzi infection (15). In this study, mRNA levels of collagen- 1 and -6 increased in the infected animals' hearts (15). These results could support our findings because collagen $\alpha-1$ is one of the proteins identified exclusively in EVs before patient treatment (Table 2).

Another important observation is the identification of a higher number of human proteins in patient-derived EVs than in the 2 healthy donor-derived EV samples (Figure 2; Appendix). Of the total proteins identified, in which statistical analysis was feasible, 4 were significantly upregulated in patientderived EVs before treatment, particularly for the proteins complement $\mathrm{C} 1 \mathrm{~s}$ subcomponent, isoform CRA_b, FLJ00385 protein, and cDNA FLJ75416 (Appendix). Complement $\mathrm{C} 1 \mathrm{~s}$ subcomponent recently 
was identified among the 6 upregulated EV biomarkers with potential for clinical applications in myocardial infarction (3).

\section{Conclusions}

Proteins associated with EVs secreted by T. cru$z i$ have been identified in the conditioned medium of different parasite stages (11-13) but not in biofluids from Chagas disease patients. We described the proteomic profiling of plasma-derived EVs purified directly from a heart transplant patient with chronic Chagas disease who exhibited reactivation after immunosuppression. We identified human and parasite proteins present or upregulated in plasmaderived EVs from a chronic Chagas disease patient before chemotherapy and that are absent or downregulated after treatment. We thus hypothesize that EV proteins released by the host or parasite during infection might be potential biomarker candidates for evaluating therapeutic response and disease outcome in chronic Chagas disease, independently of the immunologic status of patients.

Table 2. Trypanosoma cruzi and human proteins identified in plasma-derived EVs from a heart transplant patient with chronic Chagas disease before benznidazole chemotherapy but absent after treatment and in healthy donors

\begin{tabular}{|c|c|c|c|c|c|}
\hline \multirow[b]{2}{*}{ Protein name $†$} & \multirow[b]{2}{*}{ UniProt accession no. } & \multicolumn{4}{|c|}{ Unique peptides } \\
\hline & & $\begin{array}{l}\text { ChD Pre- } \\
\text { BZN } \ddagger\end{array}$ & $\begin{array}{c}\text { ChD } \\
\text { Post-BZN }\end{array}$ & $\begin{array}{c}\text { Healthy } \\
1\end{array}$ & $\begin{array}{l}\text { Healthy } \\
2\end{array}$ \\
\hline \multicolumn{6}{|l|}{ T. cruzi } \\
\hline $\begin{array}{l}\text { Pyruvate. phosphate dikinase OS = Trypanosoma cruzi } \\
\text { marinkellei } \mathrm{GN}=\mathrm{MOQ} 000480 \mathrm{PE}=3 \mathrm{SV}=1\end{array}$ & K2MVM1_TRYCR & $2(0.96)$ & 0 & 0 & 0 \\
\hline \multicolumn{6}{|l|}{ Homo sapiens } \\
\hline $\begin{array}{l}\text { Collagen } \alpha-1(\mathrm{VI}) \text { chain } \mathrm{OS}=\text { Homo sapiens } \mathrm{GN}=\mathrm{COL} 6 \mathrm{~A} 1 \\
\mathrm{PE}=1 \mathrm{SV}=3\end{array}$ & CO6A1_HUMAN & $3(1.44)$ & 0 & 0 & 0 \\
\hline $\begin{array}{l}\text { Group of Angiopoietin-related protein } 6 \text { OS }=\text { Homo sapiens } \\
\mathrm{GN}=\mathrm{ANGPTL} 6 \mathrm{PE}=1 \mathrm{SV}=1+1\end{array}$ & ANGL6_HUMAN (+1) & $3(1.44)$ & 0 & 0 & 0 \\
\hline sp|PPIA_HUMAN| & sp|PPIA_HUMAN| & $3(1.44)$ & 0 & 0 & 0 \\
\hline $\begin{array}{l}\text { Mannan binding lectin serine protease } 2 \mathrm{OS}=\text { Homo sapiens } \\
\mathrm{GN}=\mathrm{MASP} 2 \mathrm{PE}=1 \mathrm{SV}=4\end{array}$ & MASP2_HUMAN & $2(1.92)$ & 0 & 0 & 0 \\
\hline $\begin{array}{l}\text { Myosin regulatory light chain } 12 \mathrm{~B} \text { OS = Homo sapiens } \\
\mathrm{GN}=\mathrm{MYL} 12 \mathrm{~B} \mathrm{PE}=1 \mathrm{SV}=2\end{array}$ & ML12B_HUMAN & $2(1.92)$ & 0 & 0 & 0 \\
\hline $\begin{array}{l}\text { Collagen } \alpha-2(\mathrm{VI}) \text { chain } \mathrm{OS}=\text { Homo sapiens } \mathrm{GN}=\mathrm{COL} 6 \mathrm{~A} 2 \\
\mathrm{PE}=1 \mathrm{SV}=4\end{array}$ & CO6A2_HUMAN & $2(1.44)$ & 0 & 0 & 0 \\
\hline $\begin{array}{l}\text { Collectin subfamily member } 10 \text { (C-type lectin). isoform CRA_a } \\
\text { OS }=\text { Homo sapiens } \mathrm{GN}=\mathrm{COLEC} 10 \mathrm{PE}=4 \mathrm{SV}=1\end{array}$ & $\begin{array}{l}\operatorname{tr} \mid \text { A0A024R9J3|A0A02 } \\
\text { 4R9J3_HUMAN }\end{array}$ & $2(1.44)$ & 0 & 0 & 0 \\
\hline $\begin{array}{l}\text { Group of Coagulation factor XIII A chain OS }=\text { Homo sapiens } \\
\mathrm{GN}=\mathrm{F} 13 \mathrm{~A} 1 \mathrm{PE}=1 \mathrm{SV}=4+2\end{array}$ & F13A_HŪMAN (+2) & $2(1.44)$ & 0 & 0 & 0 \\
\hline $\begin{array}{l}\text { Tyrosine 3-monooxygenase/tryptophan 5-monooxygenase } \\
\text { activation protein. eta polypeptide. isoform CRA_b OS = Homo } \\
\text { sapiens } \mathrm{GN}=\text { YWHAH PE }=3 \mathrm{SV}=1\end{array}$ & $\begin{array}{l}\operatorname{tr}|A 0 A 024 R 1 K 7| A 0 A 02 \\
\text { 4R1K7_HUMAN }\end{array}$ & $2(1.44)$ & 0 & 0 & 0 \\
\hline $\begin{array}{l}\text { Fibrinogen-like protein } 1 \mathrm{OS}=\text { Homo sapiens } \mathrm{GN}=\mathrm{FGL} 1 \\
\mathrm{PE}=1 \mathrm{SV}=3\end{array}$ & FGL1_HUMAN & $2(0.96)$ & 0 & 0 & 0 \\
\hline $\begin{array}{l}\text { Group of L-lactate dehydrogenase } A \text { chain } O S=\text { Homo } \\
\text { sapiens } G N=L D H A P E=1 S V=2+1\end{array}$ & LDHA_HUMAN (+1) & $2(0.96)$ & 0 & 0 & 0 \\
\hline $\begin{array}{l}\text { Group of Laminin subunit } \alpha-2 \text { OS = Homo sapiens } \\
\mathrm{GN}=\mathrm{LAMA} 2 \mathrm{PE}=1 \mathrm{SV}=1+1\end{array}$ & $\underset{(+1)}{\operatorname{A0A087WX80} \text { HUMAN }}$ & $2(0.96)$ & 0 & 0 & 0 \\
\hline $\begin{array}{l}\text { Group of MHC class I antigen (Fragment) } O S=\text { Homo sapiens } \\
\text { GN }=H L A-A P E=3 S V=1+3\end{array}$ & $\begin{array}{c}\operatorname{tr|D2KZ27|D2KZ27}- \\
\text { HUMAN (+3) }\end{array}$ & $2(0.96)$ & 0 & 0 & 0 \\
\hline $\begin{array}{l}\text { Group of Serum amyloid } A \text { protein } \mathrm{OS}=\text { Homo sapiens } \\
\mathrm{GN}=\mathrm{SAA} 1 \mathrm{PE}=1 \mathrm{SV}=1+2\end{array}$ & E9PQD6_HUMAN (+2) & $2(0.96)$ & 0 & 0 & 0 \\
\hline $\begin{array}{l}\text { Group of Transforming growth factor } \beta \text {-induced } 68 \mathrm{kDa} \\
\text { isoform } 2 \text { (Fragment) OS = Homo sapiens } \mathrm{GN}=\mathrm{TGFBI} \\
\mathrm{PE}=2 \mathrm{SV}=1+1\end{array}$ & $\begin{array}{l}\operatorname{tr|A0A0S2Z4K6|A0A0S~} \\
\text { 2Z4K6_HUMAN (+1) }\end{array}$ & $2(0.96)$ & 0 & 0 & 0 \\
\hline $\begin{array}{l}\text { Heparan sulfate proteoglycan } 2 \text { (Perlecan). isoform CRA_b } \\
\mathrm{OS}=\mathrm{Homo} \text { sapiens } \mathrm{GN}=\mathrm{HSPG} 2 \mathrm{PE}=4 \mathrm{SV}=1\end{array}$ & $\begin{array}{l}\operatorname{tr}|A 0 A 024 R A B 6| A 0 A 02 \\
\text { 4RAB6_HUMAN }\end{array}$ & $2(0.96)$ & 0 & 0 & 0 \\
\hline $\begin{array}{l}\text { Neurogenic locus notch homologue protein } 3 \mathrm{OS}=\text { Homo } \\
\text { sapiens } \mathrm{GN}=\mathrm{NOTCH} 3 \mathrm{PE}=1 \mathrm{SV}=2\end{array}$ & NOTC3_HUMAN & $2(0.96)$ & 0 & 0 & 0 \\
\hline $\begin{array}{l}\text { V1-16 protein (Fragment) OS = Homo sapiens } \mathrm{GN}=\mathrm{V} 1-16 \\
\mathrm{PE}=4 \mathrm{SV}=1\end{array}$ & $\begin{array}{l}\operatorname{tr}|Q 5 N V 81| Q 5 N V 81 \\
\text { HUMAN }\end{array}$ & $2(2.88)$ & 0 & 0 & 0 \\
\hline $\begin{array}{l}\text { Rheumatoid factor RF-ET6 (Fragment) OS = Homo sapiens } \\
\mathrm{PE}=2 \mathrm{SV}=1\end{array}$ & $\begin{array}{l}\operatorname{tr|A2J1N5|A2J1N5} \\
\text { HUMAN }\end{array}$ & $2(5.29)$ & 0 & 0 & 0 \\
\hline
\end{tabular}




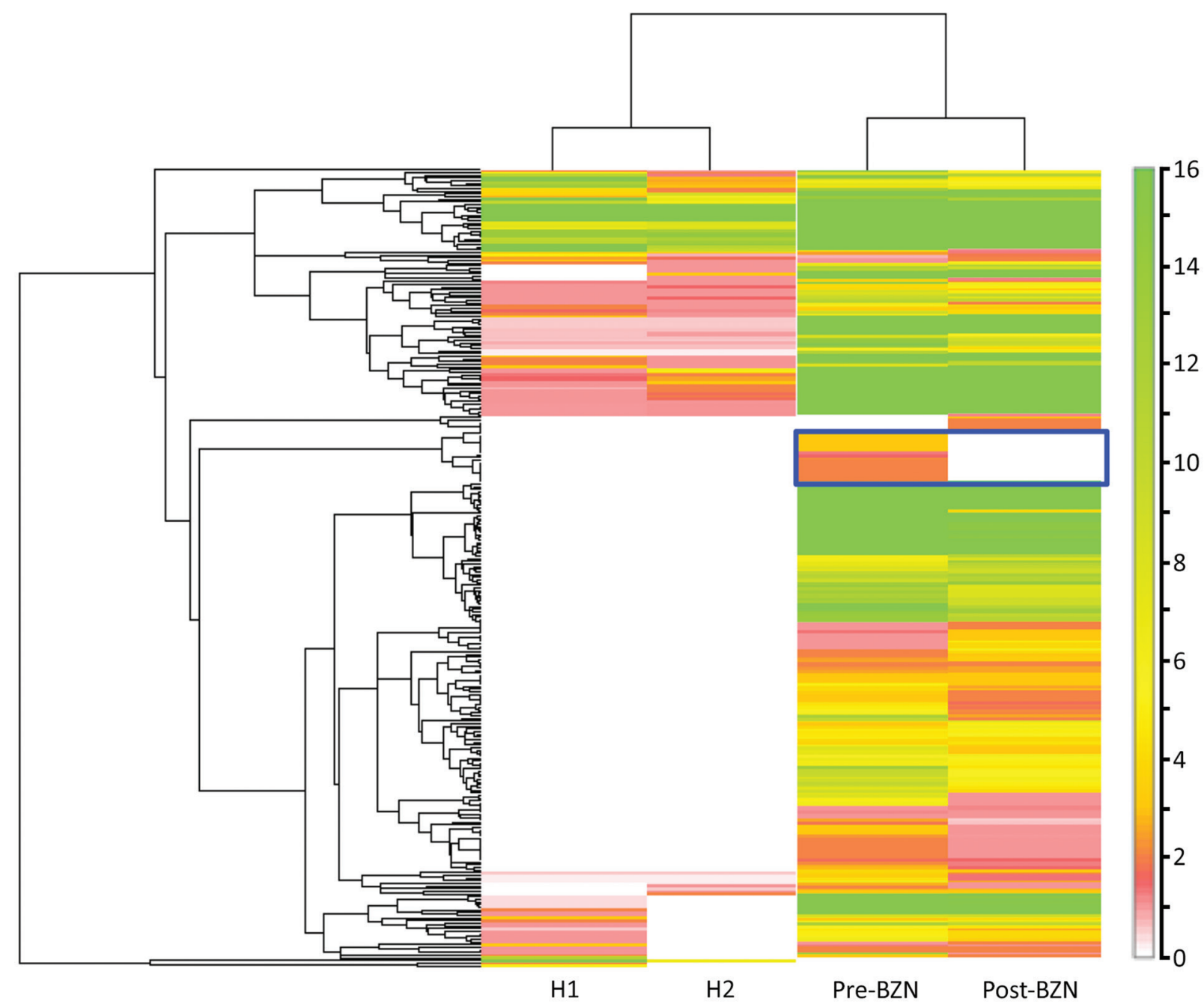

Figure 2. Human proteomic profile of plasma-derived EVs from a heart transplant patient with chronic Chagas disease before and after BZN treatment and from 2 healthy donors. Heatmap of the identified human EV-derived proteins. Heatmap was generated from proteomic data by the Scaffold perSPECtives software (Proteome Software; http://www.proteomesoftware.com). Hierarchical clustering (on the left), using single-linkage clustering with a Euclidean distance metric, was performed based on the normalized weighted spectrum counts of the identified proteins. Color gradient scale bar (Y-axis) indicates normalized spectrum counts (numerical matrix) translated into a color image, as described in the Scaffold perSPECtives version 3.0 User's Manual (http://www.proteomesoftware.com/ pdf/scaffold_perspectives_users_guide.pdf?v=232de555). More human proteins were found in EVs isolated from the patient, before and after BZN treatment than from EVs derived from the 2 healthy donors $(\mathrm{H} 1, \mathrm{H} 2)$. BZN, benznidazole; EV, extracellular vesicle.

However, our results should be interpreted with caution because they represent a single clinical case. Further research is needed to validate and provide stronger evidence that circulating EVs in patients with chronic Chagas disease can serve as biomarkers in disease progression and early assessment of therapeutic outcomes. Moreover, the future incorporation of such validated biomarkers in a point-of-care device could help in the detection of very low parasites in circulation, particularly when concentrations are below the PCR detection level (2).

\section{Acknowledgments}

We thank the patient and healthy donors who participated in this study. We are particularly grateful to Hernando A. del Portillo for helpful discussions and support throughout this project and to Marc Nicolau for technical assistance.

Barcelona Institute for Global Health (ISGlobal) receives support from the Spanish Ministry of Science, Innovation and Universities through the Centro de Excelencia Severo Ochoa 2019-2023 Program (CEX2018-000806-S). ISGlobal and Institut d'Investigació en Ciències de la Salut Germans Trias i Pujol (IGTP) are members of the Centres de Recerca de Catalunya (CERCA 
Program), Generalitat de Catalunya. Work in the laboratory of C.F.B. is funded by Fundació La Marató de TV3 (reference 566/U/2018) and Fundación Mundo Sano. This project was co-financed by the European Union through the European Regional Development Fund with the support of Secretaria d'Universitats i Recerca del Departament d'Empresa i Coneixement de la Generalitat de Catalunya. N.C., M.G., J.G., and M.J.P. receive funds from the Redes temáticas de investigación cooperativa en salud (RETICS), Spanish Tropical Diseases Network "RD12/0018/0010" and from the Agencia de Gestió d'Ajuts Universitaris i de Recerca, Generalitat de Catalunya; grant “2017 SGR 00924.” M.G., C.B., J.G., M.J.P., and I.C.A. belong to the Ibero-American Nuevas Herramientas para el Diagnóstico y la Evaluación del Paciente con Enfermedad de Chagas network. I.C.A. is partially supported by grants no. 2G12MD007592 and 5U54MD007592 from the National Institute on Minority Health and Health Disparities of the US National Institutes of Health. We are grateful to the Biomolecule Analysis Core Facility at University of Texas at El Paso, Border Biomedical Research Center, funded by National Institute on Minority Health and Health Disparities grants 2G12MD007592 and 5U54MD007592. M.T.M. received a PhD fellowship from the Science Without Borders Program, Coordenação de Aperfeiçoamento de Pessoal de Nível Superior, Brazil.

\section{About the Author}

Ms. Cortes-Serra is a PhD student in ISGlobal, Hospital Clinic-Universitat de Barcelona, Barcelona, Spain. Her research interests include extracellular vesicles and neglected infectious diseases, especially Chagas disease.

\section{References}

1. Pinazo MJ, Gascon J. The importance of the multidisciplinary approach to deal with the new epidemiological scenario of Chagas disease (global health). Acta Trop. 2015;151:16-20. https:/ / doi.org/10.1016/j.actatropica.2015.06.013

2. Pinazo MJ, Thomas MC, Bustamante J, Almeida IC, Lopez MC, Gascon J. Biomarkers of therapeutic responses in chronic Chagas disease: state of the art and future perspectives. Mem Inst Oswaldo Cruz. 2015;110:422-32. https:/ / doi.org/10.1590/0074-02760140435

3. Cheow ES, Cheng WC, Lee CN, de Kleijn D, Sorokin V, Sze SK. Plasma-derived extracellular vesicles contain predictive biomarkers and potential therapeutic targets for myocardial ischemic (MI) injury. Mol Cell Proteomics. 2016;15:2628-40. https:/ / doi.org/10.1074/ mcp.M115.055731

4. Marcilla A, Martin-Jaular L, Trelis M, de Menezes-Neto A, Osuna A, Bernal D, et al. Extracellular vesicles in parasitic diseases. J Extracell Vesicles. 2014;3:25040. https://doi.org/10.3402/jev.v3.25040

5. Rassi A Jr, Rassi A, Marin-Neto JA. Chagas disease. Lancet. 2010;375:1388-402. https:/ / doi.org/10.1016/ S0140-6736(10)60061-X
6. Pinazo MJ, Espinosa G, Gállego M, López-Chejade PL, Urbina JA, Gascón J. Successful treatment with posaconazole of a patient with chronic Chagas disease and systemic lupus erythematosus. Am J Trop Med Hyg. 2010;82:583-7. https://doi.org/10.4269/ ajtmh.2010.09-0620

7. Abras A, Ballart C, Llovet T, Roig C, Gutiérrez C, Tebar S, et al. Introducing automation to the molecular diagnosis of Trypanosoma cruzi infection: a comparative study of sample treatments, DNA extraction methods and real-time PCR assays. PLoS One. 2018;13:e0195738. https://doi.org/ 10.1371/journal.pone.0195738

8. de Menezes-Neto A, Sáez MJ, Lozano-Ramos I, Segui-Barber J, Martin-Jaular L, Ullate JM, et al. Size-exclusion chromatography as a stand-alone methodology identifies novel markers in mass spectrometry analyses of plasma-derived vesicles from healthy individuals. J Extracell Vesicles. 2015;4:27378. https:// doi.org/10.3402/jev.v4.27378

9. Yang F, Shen Y, Camp DG II, Smith RD. High-pH reversed-phase chromatography with fraction concatenation for 2D proteomic analysis. Expert Rev Proteomics. 2012;9:129-34. https:/ / doi.org/10.1586/ epr.12.15

10. Ribeiro KS, Vasconcellos CI, Soares RP, Mendes MT, Ellis CC, Aguilera-Flores M, et al. Proteomic analysis reveals different composition of extracellular vesicles released by two Trypanosoma cruzi strains associated with their distinct interaction with host cells. J Extracell Vesicles. 2018;7:1463779. https:/ / doi.org/10.1080/20013078. 2018.1463779

11. Bayer-Santos E, Aguilar-Bonavides C, Rodrigues SP, Cordero EM, Marques AF, Varela-Ramirez A, et al. Proteomic analysis of Trypanosoma cruzi secretome: characterization of two populations of extracellular vesicles and soluble proteins. J Proteome Res. 2013;12:883-97. https:// doi.org/10.1021/pr300947g

12. Bautista-López NL, Ndao M, Camargo FV, Nara T, Annoura T, Hardie DB, et al. Characterization and diagnostic application of Trypanosoma cruzi trypomastigote excretedsecreted antigens shed in extracellular vesicles released from infected mammalian cells. J Clin Microbiol. 2017;55:744-58. https:// doi.org/10.1128/JCM.01649-16

13. Mattos EC, Canuto G, Manchola NC, Magalhães RDM, Crozier TWM, Lamont DJ, et al. Reprogramming of Trypanosoma cruzi metabolism triggered by parasite interaction with the host cell extracellular matrix. PLoS Negl Trop Dis. 2019;13:e0007103. https:// doi.org/10.1371/ journal.pntd.0007103

14. Boldt AB, Luz PR, Messias-Reason IJ. MASP2 haplotypes are associated with high risk of cardiomyopathy in chronic Chagas disease. Clin Immunol. 2011;140:63-70. https://doi.org/10.1016/j.clim.2011.03.008

15. Rothfuchs AG, Roffê E, Gibson A, Cheever AW, Ezekowitz RA, Takahashi K, et al. Mannose-binding lectin regulates host resistance and pathology during experimental infection with Trypanosoma cruzi. PLoS One. 2012;7:e47835. https://doi.org/10.1371/ journal.pone.0047835

Address for correspondence: Carmen Fernandez-Becerra or María Jesús Pinazo, ISGlobal, Hospital Clinic-Universitat de Barcelona, Carrer Rosselló, 132, 6 E-08036, Barcelona, Spain; email: carmen.fernandez@isglobal.org or mariajesus.pinazo@isglobal.org 